\title{
The cost of knowledge and productivity dynamics. An empirical investigation on a panel of OECD countries
}

\author{
Cristiano Antonelli, ${ }^{\mathrm{a}, \mathrm{b}}$ and Agnieszka Gehringer ${ }^{\mathrm{c}}$ \\ ${ }^{a}$ Dipartimento di Economia, Università di Torino, Turin, Italy; ${ }^{b}$ BRICK (Bureau of Research on \\ Innovation, Complexity and Knowledge) Collegio Carlo Alberto, Moncalieri (Turin), Italy; \\ ${ }^{c}$ Flossbach von Storch Research 2 plogne, Germany
}

\section{Introduction}

Economic growth based on the continuous generation of innovation is a major contribution of the Schumpeterian legacy and endogenous growth models (Romer 1990; Rivera-Batiz and Romer 1991; Grossman and Helpman 1991; Aghion and Howitt 1992, 1998). The subsequent investigation of causes of productivity growth and of differences across regions and industries in the productivity dynamics attracted much attention in the past empirical investigations. The intensive search of the determinants of total factor productivity (TFP) lea $D$ ident such factors as R\&D efforts, human capital accumulation, trade opennes, 2013; Gehringer et al. 2015).

Little attention has been paid, so far, to the costs of knowledge. Yet, the empirical evidence confirms that the cost of knowledge differs widely over time and across countries. The variance of the costs of knowledge takes place also in countries that share similar regimes of intellectual property rights where, we can assume, the levels of knowledge appropriability are homogeneous. For given and homogeneous levels of knowledge appropriability, the difference across countries of knowledge costs can be regarded as a reliable measure of the levels of positive pecuniary knowledge externalities that the firms of each country can take advantage of.

These differences are likely to be the consequence of the quality of the knowledge governance systems at work within each country and of the levels of knowledge connectivity of the system. These differences are likely to be the cause of the innovation capability of each country and consequently of the rates of increase of its total factor productivity.

At the macro level, the unit cost of knowledge was ranging between 0.2 million of constant PPP \$ in South Korea and New Zealand to 6.2 million of constant PPP \$ in Belgium, on average between 1985 and 2010. Moreover, such costs were varying over time in the majority of the OECD countries in our sample: it was generally lower in the last decades of the twentieth century and increased significantly afterwards. We integrate this stylized fact into the analysis of productivity dynamics and treat the cost of knowledge as a new determining factor of total factor productivity growth. Accordingly, our main hypothesis is based on the following argumentation. Where the cost of knowledge is higher, more intensive $R \& D$ expenditures are needed to generate a piece of technological 


\section{STRATEGIC ALLIANCES}

knowledge. Conversely, where it costs less to engage in innovative activities, relatively more new knowledge will be generated, contributing to faster productivity growth. This hypothesis seems at the first look to be confirmed by the data, both for individual countries and for the average of the OECD sample. Regarding more precisely the development over time, although - by their nature - the growth rates of TFP were more volatile, the steadily increase in the unit cost of knowledge was accompanied by a diminishing trend of productivity growth.

The theoretical explanation of the possible link between the cost of knowledge and the productivity dynamics relies upon the notion of pecuniary knowledge externalities, according to which external technological knowledge, regarded as an indispensable input inte the generation of new technological knowledge and the eventual introduction of innovations, can be accessed and used at costs that are below equilibrium levels in some specific regional, industrial and institutional circumstances. When the private costs of knowledge lie below its social value, the unit cost of knowledge-intensive production is lower and the output larger than expected. The more intensive are knowledge externalities and the faster productivity growth of the system at large.

Our approach and the main contribution to the literature is twofold. First, we construct a broad theoretical background showing that both the recent advances of both the Schumpeterian and the Arrovian traditions of analysis support our working hypothesis. We assume that for homogeneous levels of knowledge appropriability, the costs of knowledge have a positive effect on the capability of firms to introduce productivity enhancing innovations. We build here upon two complementary models: the knowledge generation function (Nelson 1982; Weitzman 1996, 1998) and the material goods production function (Griliches 1979) that are put into a unified analytical framework. Subsequently, we empirically test our model in a panel investigation relative to 20 OECD countries, in the time span between 1985 and 2010.

The rest of the paper is organized as follows. In Section 2, we describe the relevant literature creating the conceptual context for our later analysis. Section 3 presents the theoretical model, which is then empirically tested in Section 4. Finally, Section 5 provides crucial policy implications, whereas the last section concludes.

\section{The analytical context}

The appreciation of the central role of knowledge externalities in the introduction of productivity enhancing innovations is the convergent result of the recent advances of two quite separate and yet complementary analytical approaches: i) the 'rediscovery' of Schumpeterian notion of creative reaction contingent upon the availability of knowledge externalities and ii) the Arrovian analysis of technological knowledge. Let us analyze them in turn.

\subsection{The Schumpeterian 'creative reaction'}

The new appreciation of the essay "The creative response in economic history" published by Joseph Alois Schumpeter in the Journal of Economic History in 1947 and 'almost' forgotten since then enables the reappraisal of the Schumpeterian legacy. The Schumpeterian literature has paid much attention to the contribution of Schumpeter (1942) which introduced the notions of limited appropriability of knowledge and the transient duration of the monopolistic market powers associated to the introduction of innovations. According to Schumpeter (1942) imitative entry cannot be impeded, but only delayed. Imitative entry 


\section{STRATEGIC ALLIANCES}

has direct - negative - effects on the price of innovative products. Limited appropriability, as a consequence, exerts negative pecuniary externalities.

With respect to the large literature that impinged upon 'Capitalisn fialism and

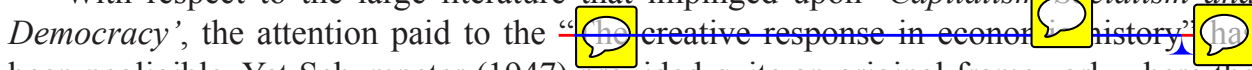
been negligible. Yet Schumpeter (1947) provided quite an original framework where the innovation is conceptualized as a creative response rather than the result of a routine or a rational plan. The availability of knowledge externalities is regarded as an indispensable condition to support the creative reaction and actually introduce technological innovations. According to Schumpeter (1947) firms are often exposed to mismatches between the plans that are necessary to organize their current business and the actual conditions of product and factor markets. Their reaction can be adaptive (or passive) and creative. Passive reactions consist in textbook switching activities on the existing maps of isoquants and adjustment of prices to quantities and vice versa. Passive reactions take place when firms cannot take advantage of knowledge externalities. Without pecuniary knowledge externalities, in fact, firms might be able to change their products and their processes, but they could not introduce technological innovations. Without pecuniary knowledge externalities firms may increase the variety of their products and production processes, but cannot introduce productivity enhancing innovations (Antonelli 2008).

Their reactions to unexpected mismatches between expectations and actual conditions of both product and factor markets are creative when and if relevant pecuniary knowledge externalities are available. Only with pecuniary knowledge externalities firms that try and react to mismatches that push them in out-of-equilibrium conditions, can introduce actual productivity enhancing technological innovations (Antonelli 2008, 2011).

The late essay of Schumpeter uncovers the positive effects of the limited appropriability of knowledge: knowledge spills as it cannot be fully appropriated by the 'inventor', reduces the price of new products, but yields positive externalities that can benefit all inventors. The notion of pecuniary knowledge externalities enables to integrate both the contributions of Schumpeter: 'Capilis negative knowledge externalities consist in the reduction of the prices and hence the revenues stemming from the introduction of an innovation. Positive pecuniary knowledge externalities consist in the reduction of the costs of knowledge that is necessary to introduce an innovation. The algebraic sum defines whether the levels of net pecuniary knowledge externalities that can be both positive or negative (Antonelli 2010).

The reappraisal of the Schumpeterian literature, based upon the appreciation of the notion of innovation as a creative respons Co tingent upon the availability of net positive pecuniary knowledge externalities, complenth and integrates the new developments of the Arrovian economics of knowledge.

\subsection{The new economics of knowledge}

Technological knowledge is a peculiar good as well as a highly idiosyncratic activity. Following the pathbreaking analysis of Kenneth Arrow and Richard Nelson it is well known that technological knowledge, as an economic good, is characterized by limited appropriability, non-exhaustivity, non-rival use, high levels of tacitness, and substantial non-divisibility (Nelson 1959; Arrow 1962, 1969). Technological knowledge is at the same time the output of a dedicated activity and a necessary input not only in the production of the other goods, but also in the generation of new technological knowledge (David 1993; Crépon, Duguet, Mairesse 1998). 


\section{STRATEGIC ALLIANCES}

The generation of technological knowledge, as a consequence, is shaped by the systematic recombination of the existing bits of knowledge together with current efforts of research, development and learning $(R \& D \& L)$ activities (Weitzman 1996, 1998; Lucas 2008).

Intrinsic external and internal cumulability shapes the recombinant generation of technological knowledge. The basic inputs into the generation of technological knowledge are not only the current flows of $R \& D \& L$ activities performed by each firm, but also the stock of existing knowledge generated internally by each firm and externally by the rest of the system (Saviotti 2007).

Due to the very characteristics of technological knowledge, its owners are unable to fully appropriate their intellectual property and, consequently, knowledge spills to the rest of the system. Because of this limited appropriability, knowledge externalities do take place (Griliches 1979, 1992). Knowledge externalities, however, only rarely take the form of pure externalities. Indeed, the access to the external sources of knowledge is not entirely free: because of relevant absorption costs, the case of pecuniary knowledge externalities applies instead (Cohen and Levinthal 1990). ${ }^{2}$

Absorption efforts are necessary to screen the existing knowledge of the other firms, identify the components that are indispensable to pursuit the on-going generation of new knowledge, access and retrieve them, and, finally, apply their content (Cohen and Levinthal 1990). Because of the irreducible content of tacitness, the access to the relevant portions of existing knowledge is possible only by means of systematic interactions and effective communication between knowledge producers and knowledge users. Knowledge interactions on their own are far from free: their successful implementation requires dedicated activities that entail specific costs (Lane 2009). The cost of such interactions - involving screening, learning, communicating and finally absorbing - is, nevertheless, below the social value of knowledge exchanged, so that pecuniary knowledge externalities are possible (Gehringer 2011).

The portions of technological knowledge acquired externally are strictly complementary to the internal knowledge stock and to the current efforts of $R \& D \& L$ in the recombinant generation of new technological knowledge. This means that firms cannot afford without external knowledge. Additionally, external knowledge brings about benefits in terms of pecuniary knowledge externalities. When and if pecuniary knowledge externalities are available and hence can be accessed, implying costs of external knowledge below the equilibrium levels, firms can introduce technological innovations that increase total factor productivity levels (Antonelli 2013a).

\subsection{Pecuniary knowledge externalities and productivity growth}

The two lines of enquiry converge with different motivations and in different analytical traditions - respectively the equilibrium and the out-of-equilibrium approach - to articulating the same hypothesis. When firms face un-expected product and factor market conditions, the costs of knowledge play a key role in shaping their reaction. When the costs of knowledge are high, firms cope with the out-of-equilibrium conditions by means of substitution processes: they try and adjust quantities to prices moving along the existing maps of isoquants. When the costs of knowledge are low, firms try and generate new technological knowledge so as to introduce innovations that change the existing map of isoquants. Their reaction can be creative only when and if the costs of knowledge are low.

Low knowledge costs make possible to try and introduce innovations rather than adjusting quantities to prices and vice versa. In order to introduce innovations, firms 


\section{STRATEGIC ALLIANCES}

activate their knowledge generation processes and make effective use of the external knowledge that is available at costs that are below equilibrium levels. Pecuniary knowledge externalities are found in innovation systems characterized by high levels of knowledge connectivity when firms can access and use the existing stocks of knowledge at low costs. High knowledge connectivity in turn depends upon the quality of knowledge interactions not only between users and producers, but at large between the variety of agents, including firms and research organizations that are part of the system. Strategic alliances aimed at implementing the knowledge capability of firms are a key determinant of the general levels of knowledge connectivity.

Total factor productivity can be explained only in terms of access to pecuniary knowledge externalities. Pecuniary knowledge externalities in fact provid foss to external knowledge at costs that are below equilibrium levels. This enables firm tope with unexpected changes in product and factor market conditions in a creative way by means of the introduction of technological and organizational innovations.

Total factor productivity measures the mismatch between historic levels actually experienced and the levels of expected (equilibrium) output. Pecuniary knowledge externalities can account for the residual. When the access and use of the external stock of knowledge costs less than in the market equilibrium conditions, the reaction of firms can be creative and the actual output levels are larger than the expected ones. Here the distinction between pure or technical externalities and pecuniary knowledge externalities plays a central role. The stock of existing knowledge can be accessed and used as an indispensable input into the generation of further knowledge only with the intentional effort of perspective users. The access itself does not fall from heaven. It is the result of intentional and dedicated activities that entail a cost. Such cost in turn depends not only on the sheer size of the stock of knowledge, but also on the structural characteristics of the system and on the quality of knowledge governance mechanisms that are in place. If we retain the notion of economic systems as rugged landscapes articulated by Krugman (1994 and 1995) we see that some systems are endowed with landscapes and connectivity levels (Page 2011) that are better able than others to make the access to existing knowledge easier and less expensive, with larger knowledge externalities, that in turn yield larger occurrence of creative reactions, decisions to innovate and ultimately higher rates of total factor productivity increase.

\section{The cost of knowledge and productivity growth}

For given and homogeneous levels of knowledge appropriability, as made possible by homogeneous intellectual property right regimes, implemented in the countries taken into consideration, the international difference of the costs of knowledge can be regarded as a reliable measure of the positive pecuniary knowledge externalities upon which the firms of each country can rely in making their creative reaction possible, supporting the generation of new technological knowledge and the consequent introduction of productivity enhancing innovations.

Building upon these assumption $\sim$ s possible to elaborate a simple model, where pecuniary knowledge externalities exp The model nests $\mathrm{s}$ of two stylized activities: a knowledge generation function and a technology production function.

Our knowledge generation function follows the analysis by Nelson (1982) and Weitzman $(1996,1998)$. The stocks of all existing technological knowledge both internal and external to each firm are indispensable, strictly complementary inputs, together with 


\section{STRATEGIC ALLIANCES}

$R \& D$ activities and the valorization of learning processes in the recombinant generation of new technological knowledge.

Internal and the external stocks of existing knowledge can be accessed only if and when dedicated resources have been expensed. We can thus write the recombinant knowledge generation function and the cost equation of technological knowledge of each firm. The knowledge generation function is a standard Cobb-Douglas and takes the following form:

$$
T K(I S K, E S K, R \& D \& L)=I S K^{A} E S K^{B} R \& D \& L^{\Delta}
$$

where $T K$ represents new technological knowledge generated with constant returns to scale by means of the current efforts in research, development and learning activities $(R \& D \& L)$, the internal stock of knowledge (ISK), the external stock of knowledge (ESK), i.e. the three indispensable factors. $A, B$ and $\Delta$ are the respective output elasticities of the three inputs. The marginal rates of technical substitution of the three factors are:

$$
\begin{gathered}
\frac{\partial T K / \partial I S K}{\partial T K / \partial E S K}=\frac{A \cdot I S K^{A-1} E S K^{B} R \& D \& L^{\Delta}}{B \cdot I S K^{A} E S K^{B-1} R \& D \& L^{\Delta}}=(A / B)(E S K / I S K) \\
\frac{\partial T K / \partial I S K}{\partial T K / \partial R \& D \& L}=\frac{A \cdot I S K^{A-1} E S K^{B} R \& D \& L^{\Delta}}{\Delta \cdot I S K^{A} E S K^{B} R \& D \& L^{\Delta-1}}=(A / \Delta)(R \& D \& L / I S K) \\
\frac{\partial T K / \partial R \& D \& L}{\partial T K / \partial E S K}=\frac{\Delta \cdot I S K^{A} E S K^{B} R \& D \& L^{\Delta-1}}{B \cdot I S K^{A} E S K^{B-1} R \& D \& L^{\Delta}}=(\Delta / B)(E S K / R \& D \& L)
\end{gathered}
$$

Denoting with $t, u$ and $z$ the unit price of the respective factors, the cost equation is:

$$
C=t I S K+u E S K+z R \& D \& L
$$

Profits can be defined as:

$$
\pi(T K)=s T K(I S K, E S K, R \& D \& L)-t I S K-u E S K-z R \& D \& L
$$

where $s$ is the price of the knowledge output.

The first order conditions of the profit maximization can be obtained by deriving (4) with respect to factors $I S K, E S K$ and $R \& D \& L$, and putting equal to zero. This can be expressed as follows:

$$
\begin{aligned}
\partial \pi / \partial I S K & =s \cdot A \cdot I S K^{A-1} E S K^{B} R \& D \& L^{\Delta}-t=0 \\
\partial \pi / \partial E S K & =s \cdot B \cdot I S K^{A} E S K^{B-1} R \& D \& L^{\Delta}-u=0 \\
\partial \pi / \partial R \& D \& L & =s \cdot \Delta \cdot I S K^{A} E S K^{B} R \& D \& L^{\Delta-1}-z=0 .
\end{aligned}
$$

From (5), the equilibrium conditions can be rewritten as follows:

$$
\begin{aligned}
t / u & =(A / B)(E S K / I S K) \\
z / t & =(A / \Delta)(R \& D \& L / I S K) \\
z / u & =(\Delta / B)(E S K / R \& D \& L)
\end{aligned}
$$

It follows that firms select the equilibrium mix of inputs such that the relative unit costs are equal to the marginal rate of technical substitution. In some localized, historic, 


\section{STRATEGIC ALLIANCES}

institutional and spatial circumstances, because of the quality of knowledge governance mechanisms at work and the high quality of knowledge interactions and communication, the unit costs of the access and re-use of the stock of existing knowledge are very low: hence reaction of firms can be creative. Pecuniary knowledge externalities are found where and when the localized costs of the stock of external knowledge $(u)$ are below socially desirable equilibrium - average - levels $\left(u^{*}\right)$.

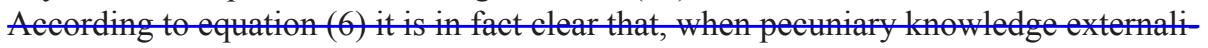
the firm will chose a combination of inputs biased towards a larger stock of external knowledge and a smaller amount of internal stocks of knowledge and of current efforts in research and development activities. When pecuniary knowledge externalities apply, as a consequence, the firm will be able to generate an amount of technological knowledge that is larger than in equilibrium conditions and will be able to react creatively so as to generate new technological knowledge at low costs and actually introduce technological innovations.

The effects of the larger amount of technological knowledge generated at costs that are lower than in equilibrium conditions, has a direct effect on the downstream production of all other goods. The recombinant knowledge generation function feeds the technology production function.

Following Griliches (1979), in fact, technological knowledge enters directly a standard Cobb-Douglas production function of all the other goods with constant returns to scale of each firm. Hence:

$$
Y(K, L, T K)=K^{\alpha} L^{\beta} T K^{\prime}
$$

where $K, L$ and $T K$ are the productive factors and $\alpha, \beta$ and $\gamma$ the respective output elasticities. The marginal rates of technical substitution are:

$$
\begin{aligned}
& \frac{\partial Y / \partial L}{\partial Y / \partial K}=\frac{\beta \cdot K^{\alpha} L^{\beta-1} T K^{\gamma}}{\alpha \cdot K^{\alpha-1} L^{\beta} T K^{\gamma}}=(\beta / \alpha)(K / L) \\
& \frac{\partial Y / \partial L}{\partial Y / \partial T K}=\frac{\beta \cdot K^{\alpha} L^{\beta-1} T K^{\gamma}}{\gamma \cdot K^{\alpha} L^{\beta} T K^{\gamma-1}}=(\beta / \gamma)(T K / L) \\
& \frac{\partial Y / \partial T K}{\partial Y / \partial K}=\frac{\gamma \cdot K^{\alpha} L^{\beta} T K^{\gamma-1}}{\alpha \cdot K^{\alpha-1} L^{\beta} T K^{\gamma}}=(\gamma / \alpha)(K / T K)
\end{aligned}
$$

Denoting with $r, w$ and $s$ the unit price of the three indispensable production factors in the production of $Y$, the cost equation is:

$$
C=r K+w L+s T K
$$

Profits can be defined as:

$$
\pi(Y)=p Y(K, L, T K)-r K-w L-s T K
$$

where $p$ is the price of the output Y.

The first order conditions can be obtained by deriving (10) with respect to factors $K, L$ and $T K$, and putting equal to zero. This can be expressed as follows: 


\section{STRATEGIC ALLIANCES}

$$
\begin{aligned}
\partial \pi / \partial K & =p \cdot \alpha \cdot K^{\alpha-1} L^{\beta} T K^{\gamma}-r=0 \\
\partial \pi / \partial L & =p \cdot \beta \cdot K^{\alpha} L^{\beta-1} T K^{\gamma}-w=0 \\
\partial \pi / \partial T K & =p \cdot \gamma \cdot K^{\alpha} L^{\beta} T K^{\gamma-1}-s=0 .
\end{aligned}
$$

From equation (11), the equilibrium conditions are:

$$
\begin{aligned}
w / r & =(\beta / \alpha)(K / L) \\
w / s & =(\beta / \gamma)(T K / L) \\
s / r & =(\gamma / \alpha)(K / T K) .
\end{aligned}
$$

Firms select the equilibrium mix of inputs such that the relative unit costs are equal to the marginal rate of technical substitution. Corresponding to these three conditions, the profit maximizing firm will identify $T K^{*}, K^{*}$ and $L^{*}$, i.e. the equilibrium levels of the production factors.

With positive pecuniary knowledge externalities in the upstream generation of technological knowledge and, hence, cheap localized costs of technological knowledge, below equilibrium level: $s<s^{*}$, firms will try and generate new technological knowledge in order to introduce innovations. Hence firms will use a technique characterized by higher levels of $T K$ and lower levels of both capital and labor: the firm will use a more knowledge intensive technique than the adaptive firms that cannot benefit from pecuniary knowledge externalities. Most importantly, the firms that benefits from pecuniary knowledge externalities will be able to react creatively to unexpected mismatches in both product and factor markets. This happens because they can generate new technological knowledge at a cost that is below equilibrium, and hence introduce productivity enhancing technological innovations, experiencing an actual increase in their levels of total factor productivity: producing an output $Y$ that is larger (and cheaper) than in general equilibrium conditions.

Following Abramovitz (1956), we know that the level of total factor productivity is measured by the ratio between the real historic levels of output $Y$, and the theoretical ones calculated as the result of the equilibrium use of production factors:

$$
A=Y / K^{*} L^{*} T K^{*}
$$

where $K^{*}, L^{*}$ and $T K^{*}$ are the general equilibrium quantities of production factors and $A$ measures total factor productivity.

Technological knowledge that has been generated without the availability of pecuniary knowledge externalities will yield equilibrium levels of output. In these conditions firms can introduce novelties, rather than innovations. Novelties consist in an increase in the variety of products and processes, such as changes in production processes, higher levels of product differentiation with new characteristics of their products. Novelties differ from innovations. The former are produced in equilibrium conditions such that the marginal product of inputs matches their costs. Innovations instead yield total factor productivity enhancing effects (Link and Siegel 2007).

The results of the modeling exercise can be summarized as it follows: firms produce more than expected and hence experience an 'un-explained' residual in the actual levels of output. The observed levels of output are larger than the expected ones $\left(Y>Y^{*}\right)$, if and when the localized costs of the access and secondary use of the stock of existing technological knowledge in the upstream knowledge generation function are lower than in general equilibrium $\left(u<u^{*}\right)$. It is clear in fact that, when pecuniary knowledge externalities apply, 


\section{STRATEGIC ALLIANCES}

the output of the recombinant knowledge generation function in terms of technological knowledge is larger than in general equilibrium conditions and the costs for the technological knowledge that enters the downstream Cobb-Douglas technology production function for all the other goods are also lower $\left(s<s^{*}\right)$. Moreover, the lower such costs, the stronger the effect of productivity increases. With a given budget, firms that benefit from pecuniary knowledge externalities are able to generate a larger amount of technological knowledge and hence an amount of all the other goods that is larger than the expected levels based upon equilibrium assumptions (Antonelli 2013a).

In such conditions, qualified by positive pecuniary knowledge externalities, each firm operates in localized (and transient) equilibrium conditions, but the aggregate output of the system is larger than expected in general equilibrium conditions. The working of pecuniary knowledge externalities is compatible with short-term, instantaneous equilibrium conditions at the firm level, while at the aggregate level the system is far from equilibrium.

This approach enables to take into account the specific characteristics of the rugged landscapes that make pecuniary knowledge externalities actually available. Pecuniary knowledge externalities, in fact, are not a ubiquitous, persistent and spontaneous attribute of any kind of economic system, at any time. Quite on the opposite, pecuniary knowledge externalities are the endogenous result of the specific conditions of the rugged landscapes into which external knowledge flows and can be accessed. The actual access to external knowledge may take place in highly localized conditions when and where knowledge cumulability is actually implemented and supported. Such characteristics, in turn, are a consequence of the past generation of technological knowledge and introduction of technological innovations. As such they are endogenous to the system (Saviotti and Pyka 2008).

\section{Empirical evidence}

\subsection{The descriptive evidence}

The empirical analysis refers to a sample of 20 industrialized OECD countries that implement and enforce a homogeneous intellectual property right regime ${ }^{3}$, observed over the time span 1985-2010. We assume that the levels of knowledge appropriability are comparable across the 20 countries considered. The unit cost of knowledge, as measured by the ratio of R\&D expenditures to patent, differs widely over time and across countries, regions, industries and firms. As Table 1 (column 1) shows, at the macro level, the unit cost of knowledge was ranging between 0.2 million of constant PPP \$ in South Korea and New Zealand to 5.5 million of constant PPP \$ in Portugal and 6.2 million in Belgium. The variance across the OECD average of 1.9 million is relevant. Moreover, such costs were varying over time in the majority of the OECD countries in our sample: it was generally lower in the first half of the period and increased significantly afterwards (Table 1, columns 1 and 2).

This dynamics over time is clearly confirmed in Figure 1. The unit cost of knowledge was steadily increasing between 1985 and 2010 for the average of our sample. For the growth of TFP the picture is less clear, although a diminishing tendency over time can be recognized.

\subsection{Estimation strategy}

Our focus is on the relationship between the unit cost of knowledge generation and the TFP growth. This relationship might in principle go two-ways. On the one hand, and in line with 


\section{STRATEGIC ALLIANCES}

Table 1. Unit cost of knowledge and TFP growth in OECD countries, 1985-2010.

\begin{tabular}{|c|c|c|c|c|c|c|}
\hline \multirow[b]{2}{*}{ Country } & \multicolumn{3}{|c|}{ Unit cost of knowledge } & \multicolumn{3}{|c|}{ TFP growth } \\
\hline & $1985-2010$ & 1985-1998 & 1999-2010 & 1985-2010 & 1985-1998 & 1999-2010 \\
\hline Australia & 0.5 & 0.5 & 0.6 & 0.9 & 1.1 & 0.5 \\
\hline Austria & 1.8 & 1.1 & 2.6 & 1.4 & 1.3 & 1.4 \\
\hline Belgium & 6.2 & 3.4 & 9.0 & 0.8 & 1.2 & 0.3 \\
\hline Canada & 0.5 & 0.4 & 0.6 & 0.4 & 0.2 & 0.5 \\
\hline Denmark & 1.7 & 1.1 & 2.5 & 0.8 & 1.1 & 0.3 \\
\hline Finland & 1.5 & 0.6 & 2.6 & 1.8 & 2.2 & 1.2 \\
\hline France & 2.1 & 1.9 & 2.4 & 1.0 & 1.4 & 0.6 \\
\hline Germany & 1.1 & 1.1 & 1.1 & 0.9 & 1.2 & 0.7 \\
\hline Ireland & 1.3 & 0.5 & 2.1 & 2.7 & 3.5 & 1.8 \\
\hline Italy & 1.8 & 1.6 & 2.0 & 0.4 & 1.0 & -0.3 \\
\hline Japan & 0.3 & 0.3 & 0.3 & 1.4 & 1.8 & 0.9 \\
\hline Korea & 0.2 & 0.3 & 0.2 & 3.8 & 4.3 & 3.3 \\
\hline Netherlands & 3.4 & 2.9 & 3.9 & 1.0 & 0.9 & 1.1 \\
\hline New Zealand & 0.2 & 0.1 & 0.2 & 0.5 & 0.5 & 0.4 \\
\hline Portugal & 5.5 & 2.6 & 8.8 & 1.3 & 2.5 & 0.6 \\
\hline Spain & 2.8 & 1.9 & 3.9 & 0.5 & 1.0 & -0.1 \\
\hline Sweden & 2.5 & 1.3 & 3.4 & 0.9 & 0.7 & 1.2 \\
\hline Switzerland & 2.3 & 1.4 & 3.4 & 0.0 & -0.6 & 0.4 \\
\hline UK & 1.1 & 0.9 & 1.3 & 0.8 & 0.8 & 0.7 \\
\hline US & 1.1 & 1.3 & 0.9 & 1.1 & 0.9 & 1.4 \\
\hline average OECD & 1.9 & 1.3 & 2.6 & 1.1 & 1.4 & 0.8 \\
\hline
\end{tabular}

Note: Unit cost of knowledge is calculated as the ratio between the total R\&D expenditures in million of constant (2005) PPP \$ and the number of patent applications made to WIPO. TFP growth is the growth rate of multi-factor productivity in per cent.

Source: own calculations based on the IPER database build upon OECD STAN and World Intellectual Property Organization (WIPO) data.

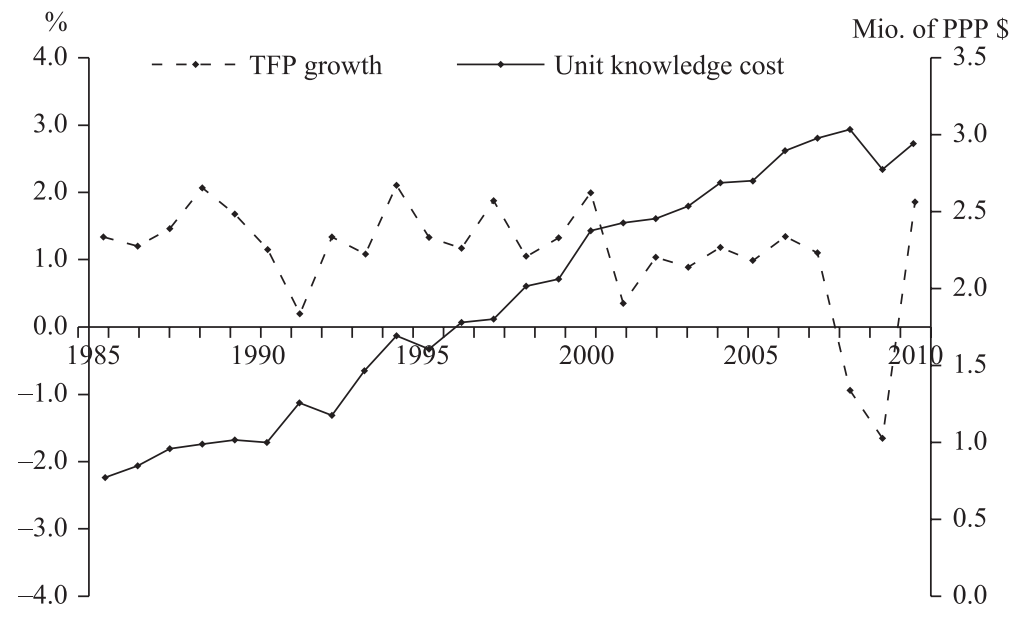

Figure 1. Development of TFP growth and of the unit cost of knowledge on average of 20 OECD countries, 1985-2010.

Note: See note of Table 1.

Source: own calculations based on the IPER database build upon OECD STAN and WIPO data. 


\section{STRATEGIC ALLIANCES}

our previous argument, where the cost of knowledge is lower, the more intensive and stronger will be pecuniary knowledge externalities and the faster should be the growth of TFP. On the other hand, in a context characterized by a positive dynamics of TFP, the costs of knowledge generation are likely to decrease due to the more extensive availability of newly generated external knowledge. Although we believe that this second mechanism is less likely to be true, or at least not on a regular basis, we account for this potential simultaneity by applying the instrumental variable method (also called two stage least squares, 2SLS), where the cost of knowledge is treated as an endogenous regressor and needs to be instrumented.

It is a common problem to find variables serving as valid instruments, in the sense of being satisfactorily exogenous with respect to the dependent variable and at the same time strongly correlated with the endogenous regressors. If instruments are weak, the precision of instrumental variable estimations is lower than that of simple OLS regressions. On the other hand, if endogenous regressors are included in the estimation, OLS results will be biased. As we suspect - and confirm with a test - that endogeneity could be an issue in our framework, we aim to explicitly deal with it, but at the same time assure that our procedure doesn't lead to of precision of our estimations.

In order to lement this approach, our econometric model is based upon a system of two equations: the cost of knowledge equation and the total factor productivity equation, where the second-step TFP growth equation includes the fitted values of knowledge cost from the first step. The two-step model can be represented in the following system:

$$
\begin{gathered}
C K_{i t}=\alpha_{1}+\alpha_{2} \text { STOCK }_{i t}+\alpha_{3}++\mathrm{V}_{\mathrm{it}}^{\prime} \alpha_{4}+\alpha_{5} C K_{i t-1}+\alpha_{6} C K_{i t-2}+\tau_{t}+\rho_{i}+\varepsilon_{i t} \\
\Delta T F P_{i t}=\beta_{1}+\beta_{2} \widehat{C K}_{i t}+\mathbf{V}_{\mathrm{it}}^{\prime} \beta_{3}+\vartheta_{t}+\mu_{i}+\varepsilon_{i t} .
\end{gathered}
$$

The first step described in equation (14) consists in testing the key hypothesis that the cost of knowledge $(C K)$ reflects the density of the stock of existing knowledge (STOCK). Each firm at each point in time will be better able to generate technological knowledge the larger the amount of pecuniary knowledge externalities. The latter in turn are likely to stem diachronically from the stock of existing knowledge. Hence we expect that the costs of knowledge in a country are lower, the larger is the stock of patents per capita. In addition to the two aforementioned instruments (the so called excluded instruments), we include the first and the second lag of the dependent variable. Vector $\mathbf{V}_{\mathrm{it}}^{\prime}$ is the set of exogenous covariates that should be in both the first and the second stage (Angrist and Pischke 2008). Finally, $\tau_{t}$ and $\rho_{i}$ are the time and country specific effects, whereas $\varepsilon_{i t}$ is the indiosyncratic error term.

A comment is due here to our measure of the cost of knowledge. This is captured by the R\&D expenditures made in a country per unit of patent and thus most closely refers to what we called in our theoretical discussion 'internal cost of knowledge'. Ideally, we would be willing to have a measure of cost that is an average between internal and external cost of knowledge generation, where external cost refers to the cost necessary to support when acquiring knowledge from sources external to the own business. However, there are insuperable limits in finding such a measure and we are constrained to stick to R\&D expenditures only. ${ }^{4}$ This notwithstanding, even for our R\&D unit cost variable, our main hypothesis always holds: given the availability of pecuniary knowledge externalities, in any instant of time firms face a cost advantage associated with external knowledge, which provides them the incentive to adjust their production plans towards a higher relative implementation of external versus internal knowledge. It follows thus that the more 


\section{STRATEGIC ALLIANCES}

abundant are knowledge externalities, the lower should be the unit cost of (internal) knowledge and the higher will be productivity growth.

In the second step, we account for the endogeneity of the costs of knowledge within the productivity equation. In order to validate our instrumenting strategy, we implement different post estimation diagnostics (precisely, weak instruments test, over-identification test, redundancy test), reported at the bottom of the results tables. Additionally, we check whether our excluded instrumental variables affect the dependent variable only indirectly, by including them as regressors in the estimations of TFP growth. ${ }^{5}$ We could confirm that these variables were not directly influential on TFP growth and, thus, the exclusion restriction cannot be rejected. ${ }^{6}$

More precisely regarding the second stage, in addition to our main explanatory variable, we account for other possible factors determining TFP growth, as suggested in the past literature. Finally, our econometric model assumes the following form:

$$
\Delta T F P_{i t}=\beta_{1}+\beta_{2} \widehat{C K}_{i t}+\beta_{3} H C_{i t}+\beta_{4} T O_{i t}+\beta_{5} G D P / \operatorname{cap}_{i t}+\vartheta_{t}+\mu_{i}+\varepsilon_{i t}
$$

where $\triangle T F P_{i t}$ is the annual growth rate of TFP in country $i$ at time $t, \widehat{C K}_{i t}$ is our variable of interest expressing the unit cost of knowledge generation, $H C_{i t}$ is a measure of human capital stock available in an economy, $T O_{i t}$ refers to a measure of trade openness and GDP/ cap $_{i t}$ refers to national income per capita. The detailed description of the variables and the indication of the data source are offered in Table 2.

Coefficient $\beta_{1}$ is a constant, whereas coefficients $\beta_{2}$ to $\beta_{5}$ are supposed to measure the marginal contribution of each factor to TFP growth. Finally, $\vartheta_{t}$ and $\mu_{i}$ are the time and country dummies, respectively, whereas $\varepsilon_{i t}$ is the idiosyncratic error term.

To justify our set of control variables, the motivation to include a measure of trade openness, as expressed in terms of the share of the overall trade volume (imports plus

Table 2. Variables used in the estimations: description and data sources.

\begin{tabular}{|c|c|c|}
\hline Variable & Description & Source \\
\hline$\triangle(T F P)$ & Growth rate of TFP & OECD.stat \\
\hline$C K$ & $\begin{array}{l}\text { Cost of knowledge, measured in terms of the } \\
\text { ratio between R\&D spending and the } \\
\text { number of patent applications in a country } \\
\text { each year between 1985-2010 }\end{array}$ & $\begin{array}{l}\text { Own calculation based } \\
\text { on OECD.stat (R\&D } \\
\text { spending) and WIPO } \\
\text { (patent applications) }\end{array}$ \\
\hline TO & $\begin{array}{l}\text { Openness to trade measured as the ratio } \\
\text { between the sum of imports and exports over } \\
\text { GDP }\end{array}$ & Penn World Tables 7.1 \\
\hline$H C$ & $\begin{array}{l}\text { Human capital: R\&D personnel per } 1000 \text { of } \\
\text { employment }\end{array}$ & OECD.stat \\
\hline GDP/cap & GDP per capita & $\begin{array}{r}\text { Own calculation based on } \\
\text { Penn World Tables } 7.1\end{array}$ \\
\hline \multicolumn{3}{|c|}{ Excluded instrument: } \\
\hline$\overline{S T O C K}$ & Patent stock per capita & $\begin{array}{l}\text { Patent stock comes from } \\
\text { own calculations } \\
\text { applying the Perpetual } \\
\text { Inventory Method on } \\
\text { annual patent applica- } \\
\text { tions to WIPO* }\end{array}$ \\
\hline
\end{tabular}

Note: * A detailed description of the method is included in Appendix B. 


\section{STRATEGIC ALLIANCES}

exports) relative to the size of the economy (GDP), derives from the fact that the intensifying trade integration between economies has been often argued to have a positive impact on productivity growth. This impact can be direct - when the trade flows (particularly export) take place in technology intensive sectors - and indirect - through the acquisition of specialized technological skills, as a consequence of interactions between the trade partners (see López 2005 for a survey of the related literature).

The inclusion of human capital directly derives from the models of endogenous growth, supportive for the positive role in the growth process played by the accumulation of skills (Lucas 1998). We measure the stock of human capital as the ratio of the R\&D personnel for 1000 of employees. In that way, we aim to capture the influence of the skilled labor that most intensively is involved in innovative processes. ${ }^{7}$

Finally, we include GDP per capita, in order to account for the convergence process. More precisely, economies that are at a relatively lower stage of their economic development (corresponding to a lower GDP per capita level) are supposed to experience a relatively faster productivity growth. Alternatively, another way to control for the possible differences in economic development and their influence on the speed of productivity growth, ene could include the initial levels of TFP. Accordingly, we checked this hypothesis as well (see the results below), but the coefficient on this variable, although reporting the right sign, was never significant.

Table 3 presents the summary statistics of the variables included estimations. Regarding the main variables of interest, the average annual growth rate of TFP was equal to $1.1 \%$, ranging between the minimum of $-7.8 \%$ to a maximum of $7.8 \%$. The unit cost of knowledge was on average equal to almost 2 millions of constant PPP \$, with a minimum of 0.09 and a maximum of 10.9 millions of PPP \$.

\subsection{Results}

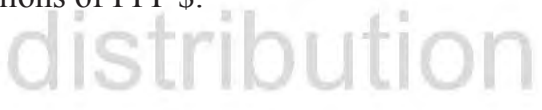

Table 4 summarizes the results of the estimations of equation (16). We report the results from four different methods. In column 1, we show the estimation results from a pooled OLS method. In columns 2 and 3, we estimate analogous specifications with methods extran accounting for the panel structure of our dataset, namely, random effects and fixed effects model. The results from these three methods serve to sort out the direction of the bias with respect to the instrumental variable estimates (i.e. 2SLS) reported in columns 4-6.

More precisely regarding the IV estimations, we first estimate a model where we include only the instrumented knowledge cost variable (column 4). This is to show the direct impact of the variable of interest on TFP growth. In other words, this is the effect of

Table 3. Summary statistics.

\begin{tabular}{lcrrrr}
\hline Variable & Obs. & Mean & Std. Dev. & Min. & Max. \\
\hline$\triangle(T F P)$ & 469 & 1.11 & 1.71 & -7.8 & 7.8 \\
$C K$ & 451 & 1.96 & 2.08 & 0.09 & 10.93 \\
$T O$ & 520 & 69.16 & 33.90 & 16.00 & 183.30 \\
$H C$ & 404 & 10.77 & 4.05 & 2.44 & 24.73 \\
GDP/cap & 520 & 27559.24 & 6731.22 & 7352.31 & 47134.06 \\
STOCK & 484 & 7471.04 & 11062.42 & 150.15 & 58820.32 \\
$R \& D$ & 457 & 554.91 & 281.11 & 42.07 & 1265.10 \\
\hline
\end{tabular}




\section{STRATEGIC ALLIANCES}

Table 4. Results of the estimations of the link between the cost of knowledge generation and productivity dynamics.

\begin{tabular}{|c|c|c|c|c|c|c|}
\hline & (1) & (2) & (3) & (4) & (5) & (6) \\
\hline & POLS & RE & $\mathrm{FE}$ & IV & IV & IV \\
\hline$C K$ & $\begin{array}{l}-0.274 * * * \\
(0.044)\end{array}$ & $\begin{array}{l}-0.196^{* * *} \\
(0.071)\end{array}$ & $\begin{array}{l}-0.199 * * * \\
(0.087)\end{array}$ & $\begin{array}{l}-0.342 * * * \\
(0.090)\end{array}$ & $\begin{array}{l}-0.354 * * * \\
(0.079)\end{array}$ & $\begin{array}{l}-0.354 * * * \\
(0.079)\end{array}$ \\
\hline TO & $\begin{array}{l}0.018^{* * * *} \\
(0.003)\end{array}$ & $\begin{array}{l}0.021 * * * \\
(0.007)\end{array}$ & $\begin{array}{l}0.029 * * \\
(0.013)\end{array}$ & & $\begin{array}{l}0.025^{* * * *} \\
(0.008)\end{array}$ & $\begin{array}{l}0.025^{* * * *} \\
(0.008)\end{array}$ \\
\hline$H C$ & $\begin{array}{c}0.039^{*} \\
(0.021)\end{array}$ & $\begin{array}{c}0.062^{*} \\
(0.036)\end{array}$ & $\begin{array}{c}0.081 \\
(0.050)\end{array}$ & & $\begin{array}{c}0.053 \\
(0.054)\end{array}$ & $\begin{array}{c}0.053 \\
(0.054)\end{array}$ \\
\hline GDP/cap & $\begin{array}{l}-0.120^{* *} \\
(0.020)\end{array}$ & $\begin{array}{l}-0.089 * * \\
(0.025)\end{array}$ & $\begin{array}{l}-0.088^{* *} \\
(0.042)\end{array}$ & & $\begin{array}{l}-0.144 \\
(0.030) * * *\end{array}$ & \\
\hline Initial TFP & & & & & & $\begin{array}{l}-51.05 \\
(82.64)\end{array}$ \\
\hline N. obs. & 360 & 360 & 360 & 280 & 255 & 255 \\
\hline R-sq. (overall) & 0.422 & 0.389 & 0.337 & 0.585 & 0.632 & 0.632 \\
\hline Hansen J & & & & 0.111 & 0.993 & 0.993 \\
\hline Weak identif. & & & & 185.64 & 145.18 & 142.00 \\
\hline $\begin{array}{l}\text { Endogeneity } \\
\text { test }\end{array}$ & & & & 0.014 & 0.009 & 0.009 \\
\hline $\begin{array}{l}\text { Redundancy } \\
\text { test }\end{array}$ & & & & 0.009 & 0.004 & 0.004 \\
\hline First stage res & he & d instr & tits. & 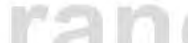 & $=6$ & \\
\hline STOCK & & & & $\begin{array}{c}-0.00002 * * * \\
(5.73 \mathrm{e}-06)\end{array}$ & $\begin{array}{c}-0.00002 * * * \\
(7.47 \mathrm{e}-06)\end{array}$ & $\begin{array}{c}-0.00003^{* * *} \\
(7.47 \mathrm{e}-06)\end{array}$ \\
\hline$C K_{t-1}$ & & & & $\begin{array}{l}0.813 * * * \\
(0.050)\end{array}$ & $\begin{array}{l}0.788^{* * *} \\
(0.053)\end{array}$ & $\begin{array}{l}0.788 * * * \\
(0.053)\end{array}$ \\
\hline$C K_{t-2}$ & & & $y$ & $\begin{array}{l}-0.015 \\
(0.020)\end{array}$ & $\begin{array}{c}-0.067 * * \\
(0.027)\end{array}$ & $\begin{array}{l}-0.067 * * \\
(0.027)\end{array}$ \\
\hline Partial R-sq. & & & & 0.848 & 0.837 & 0.837 \\
\hline
\end{tabular}

Note: Dependent variable is the growth rate of TFP. In column 1, pooled OLS results are shown. In columns 2 and 3, panel data random effects (RE) and fixed effects (FE) models are estimated. In columns 4-6 IV (2SLS) estimations are reported. The endogenous regressor, $C K$, is instrumented with its first and second lag, as well as with patent stock per capita and R\&D expenditures per capita. Weak identification test reports the Kleibergen-Paap rk Wald F statistics. Hansen $\mathrm{J}$ is the Chi-sq. p value of the overidentification test of all instruments. Endogeneity test reports the p-value of the Chi-surest having under the null the hypothesis that $C K$ is exogenous. Redundancy test reports p-value of the Chi-ext that checks, whether the excluded instruments (patent stock per capita and R\&D expenditures per capita) are redundant. Partial R-sq. refers to the goodness-of-fit of the excluded instruments. In all specifications, time and country specific effects are included. Heteroskedasticity and autocorrelation robust statistics are reported.

the cost of knowledge disconnected from the influence coming from other factors. We then include other factors in the subsequent two specifications. In column 5, openness to trade, human capital and GDP per capita are considered. Finally, in column 6, the latter variable is replaced with the initial value of TFP.

As the endogeneity test regarding the endogenous regressor $(C K)$ in all cases and at all conventional significance levels clearly rejects the null hypothesis of exogeneity, the IV specifications are preferred over those run according to the alternative methods, OLS, RE and FE. Regarding the direction of bias, the latter methods seem to underestimate the effect of knowledge cost on TFP growth. Moreover, considering the other tests reported (Hansen $\mathrm{J}$ test of validity of the overidentifying restrictions and the Kleibergen-Paap test of weak instruments), they suggest that the IV estimations are correctly specified. ${ }^{8}$ 


\section{STRATEGIC ALLIANCES}

The results clearly suggest that the effect of knowledge cost on TFP growth is negative, meaning that the higher the unit cost of generating new knowledge the lower the rate of growth of TFP. In quantitative terms, this impact ranges between -0.35 and -0.36 , depending on the control variables included. If the unit cost of knowledge increases by one unit (corresponding to one million of 2005 constant PPP \$), this leads to a $0.35-0.36$ percentage point decrease in the growth rate of TFP. Consequently, given that between 1999 and 2010 the unit cost of knowledge for the average of the OECD countries in our sample increased by around 1.3 million of PPP $\$$, this contributed to the reduction in the growth rate of TFP by approximately 0.42 percentage points. If the cost of knowledge remained unchanged at the average level from the pre-period (1985-1998), then ceteris paribus TFP would have grown on average between 1999 and 2010 at the rate of $1.2 \%$.

Regarding the other factors explaining the TFP growth, trade openness was positively contributing to speeding up TFP growth. Human capital variable, although reporting the expected positive sign, remained always insignificant. Finally, the convergence hypothesis seems to be confirmed by the negative sign of the coefficient corresponding to GDP per capita. Accordingly, countries experiencing lower levels of GDP per capita could register higher TFP growth rates. This same direction of influence, although with insignificant estimated coefficient, is found for the variable measuring the initial level of TFP.

Finally, the results of the first stage estimation relative to the excluded instruments are also reported. They confirm that the cost of knowledge diminishes as stoct knowledge increases.

\section{Conclusions and policy implications}

The empirical evidence, based upon a representative group of 20 OECD countries for the considerable stretch of 26 years, comprised between 1985 and 2010, has confirmed that knowledge costs, as measured by the ratio of total research and development expenditures to patents, vary widely across countries and over time. Moreover, this variation explains much of the dynamics in the growth rate of total factor productivity. In particular, where and when knowledge costs are lower, TFP growth is faster.

This evidence confirms the intuition, elaborated in this chapter, that knowledge costs are a key determinant of the capability of a system to support the creative reaction of firms and the rates of introduction of productivity enhancing innovations. For given levels of knowledge appropriability, the costs of knowledge depend upon the connectivity of the system. Countries that have been able to elaborate efficient knowledge governance mechanisms, making possible to firms to access and use again the existing stocks of knowledge, experience faster rates of introduction of technological innovations and higher levels of total factor productivity growth.

Pecuniary knowledge externalities are indeed external to each firm, but endogenous to the system. At each point in time and in space, in fact, the levels of pecuniary knowledge externalities do not fall from heaven like manna but depend upon the amount of innovative efforts made by agents in the system and knowledge connectivity of the system as shaped by the structure of knowledge interactions and transaction that relate each firm to the others and the business sector to the public research infrastructure.

The access to the stock of existing knowledge, in fact, is neither free nor automatic nor homogeneous across economic systems. It depends upon quality of the rugged landscapes into which the generation of technological knowledge takes place and it requires a wide range of dedicated activities including searching, screening, decoding, interacting and learning. The innovative capability of a system is influenced by the levels of its knowledge connectivity. 


\section{STRATEGIC ALLIANCES}

The policy implications of our analysis are most important. The improvement of the knowledge governance mechanisms aimed at increasing the knowledge connectivity of the system should be a crucial ingredient of innovation policymaking. The new strategic alliances play a central role in this context as they enable the direct and systematic interaction between the academic sources of scientific knowledge and their users contributing to the persistent access to the external stock of existing knowledge at low costs and hence to the reduction of the cost of knowledge generation. Consequently, they yield substantial support to the eventual increase of the rate of introduction of innovations and are able to account for the persistent increase of the general efficiency of the economic system.

Knowledge transfer policy interventions finalized to increase the knowledge connectivity of the system and hence to favor the transfer, dissemination and actual access to the stock of existing knowledge may be very effective as their ultimate effects is the reduction of the cost of knowledge, the increase of pecuniary knowledge externalities and the eventual increase of total factor productivity.

Such knowledge transfer policy interventions should primarily focus the large public research infrastructures, with the aim to make the technological knowledge generated by the public research system better accessible to perspective users. The systematic encouragement to academic departments to enter the markets for knowledge intensive business services can help small and medium sized firms to take advantage of the stock of knowledge existing within the academic walls. At the individual level, the extension of the professors' privilege so as to favor their professional activity in the markets for knowledge intensive business services should increase the interactions of the scientific personnel with the business community and put in motion the exchange of creative and praxis oriented ideas. In this context the new strategic alliances are a major organizational innovation that helps increasing the knowledge connectivity of the systen oring the reduction of the costs of knowledge.

More intense interactions and transactions between the public research system and the business community favored by the new strategic alliances, help to better focus the research activity of the public research system directing it towards scientific fields that are more likely to yield 'useful' knowledge. The identification of the appropriate portfolio of research activities able to pursue scientific progress and yet to contribute economic growth is a major problem of the public research system. The feedback from the business community expressed by the intensity of academic outsourcing and knowledge transactions may provide useful signals to grasp the actual scope of application of the different scientific fields.

With respect to the private sector knowledge transfer, policy interventions should focus on intellectual property right regimes. The introduction of subsidies to the purchase of intellectual property rights, next to the classical subsidies to the funding of R\&D activities, might help the dissemination of the existing stock of knowledge and its easier accesstransactions in the markets for intellectual property right $\mathrm{m}$ positive effects on both the demand and the supply side. The further reduction constraints of competition policies can favor the cooperation between knowledge users and knowledge producers along increasing knowledge interactions. As a third step, the structure of intellectual property right regimes might be reconsidered with respect to their exclusivity. The intellectual property right regimes play an important role. Exclusive, long-lasting intellectual property right regimes may delay the access to the stock of existing knowledge to the point that perspective users may prefer to re-invent the existing non-accessible knowledge. For given levels of the stock of existing knowledge 


\section{STRATEGIC ALLIANCES}

the systems endowed with an organized architecture of knowledge interactions and transactions may experience higher levels of pecuniary knowledge externalities that systems where knowledge interactions and transactions are made expensive by
excess opportunism.

The weakening of intellectual property rights might entail a reduction in the incentives to generate technological knowledge with the ultimate perverse effect of increasing the access to existing knowledge and hence reducing both the costs of knowledge but decreasing the incentives and hence the amount of knowledge actually generated. The introduction of compulsory licensing based upon the reduction of the exclusivity of intellectual property rights accompanied by the identification of correct levels of royalties; hover, might help the knowledge connectivity of the system favoring the dissemination of existing knowledge yet defending its appropriability. The identification of the correct levels of royalties is clearly crucial to combine the need to secure the rewards to innovators, with the goal of increasing as much as possible the social surplus stemming from the introduction of innovations (Antonelli 2013b).

\section{Acknowledgements}

The authors acknowledge the institutional support of the research project 'Incentive Policies for European Research' (IPER) and the funding of the European Union D.G. Research with the Grant number 266959 to the research project 'Policy Incentives for the Creation of Knowledge: Methods and Evidence' (PICK-ME), within the context of the Cooperation Program / Theme 8 / Socio-economic Sciences and Humanities (SSH), both in progress at the Collegio Carlo Alberto and the University of Torino.

The paper benefited much from the insightful comments and suggestions received from Gary Jeffersen, Filippo Belloc, Albert Link and other participants at the INFER Annual Conference in Pescara, May 2014 and at the Governance of a Complex World Eonference in Torine, June 2014.

\section{Notes}

1. See Gehringer et al. (2014) for an overview of the relevant literature.

2. The distinction between pure (or technological) externalities and pecuniary externalities dates back to Tibor Scitovski. Pure externalities are found when inputs can be used at no costs. Pecuniary externalities take place when the actual costs of an input, in a specific and localized condition, are lower than in equilibrium conditions (Scitovski 1954; Antonelli 2008).

3. The countries included are: Australia, Austria, Belgium, Canada, Denmark, Finland, France, Germany, Ireland, Italy, Japan, Korea, the Netherlands, New Zealand, Portugal, Spain, Sweden, Switzerland, the United Kingdom and the United States.

4. There are other problems with this measure of knowledge cost as well. First, not all R\&D activities internal to the firms are aimed to patent production, as they might end in other productive outcomes, like trade secrets, trademarks or other legally unprotected forms of innovation. This potentially leads us to over-estimate the true cost of knowledge. Second, not all patents needs formal R\&D expenditures, yet other forms of innovative investment. There might be patented incremental innovations obtained without R\&D efforts. This could lead us to underestimate the real cost of knowledge. Finally and related to the previous two points, we standardize our total cost of knowledge by the number of patents, whereas other non-patented innovations are common.

5. For brevity, we do not report the results of the aforementioned estimations here. They are available upon request.

6. This is also confirmed by the very low pair-wise correlation between the excluded instruments and $\triangle \mathrm{TFP}$, as shown in the correlation matrix in Table A.1 in Appendix A.

7. It is not easy to find a good variable measuring the stock of human capital available in the economy. It has been a common practice in the past literature to measure human capital in terms 


\section{STRATEGIC ALLIANCES}

of secondary school attainment. Nevertheless, it can be argued that it is a too broad definition of human capital and more qualified and more specific skills are essential when trying to grasp the influence of human capital on productivity. Consequently, our measure of human capital expresses an attempt in this direction. However, it can be argued that human capital is a measure of R\&D intensity and as such could be correlated with our measure of unit cost of knowledge. We checked for this possibility and found a very low and insignificant correlation between the two.

8. More precisely, the Hansen $J$ test regresses the residuals from the IV estimation on all instruments (included and excluded). The null hypothesis is then that all instruments are uncorrelated with the residuals. Thus, given that we cannot reject the null, we can conclude that our overidentifying restrictions are valid. The Kleibergen-Paap rk Wald F test statistic refers to the weak identification test proposed by Stock and Yogo (2005). The test statistic is confronted with (different levels of) the rejection rate $r$ that the researcher tolerates. Under the null, the test rejects too often. To reject the null, the F test statistic must exceed the critical value. In our case, we are always able to reject the null.

\section{References}

Abramovitz, M. 1956. "Resources and output trends in the US since 1870." American Economic Review 46, 5-23.

Abramovitz, M. 1989. Thinking about Growth. Cambridge: Cambridge University Press.

Aghion, P., and P. Howitt. 1992. "A model of growth through creative destruction." Econometrica 60, 323-351.

Aghion, P., and P. Howitt. 1998. Endogenous Growth Theory. Cambridge, MA: MIT Press.

Antonelli, C. 2008. Localized Technological Change: Towards the Economics of Complexity. London: Routledge.

Antonelli, C. 2010. "Pecuniary externalities and the localized generation of technological knowledge.," in Martin, R., and R. Boschma, (eds.), The Handbook of Evolutionary Economic Geography. Cheltenham: Edward Elgar, pp. 162-181.

Antonelli, C. (ed.), 2011. Handbook on the Economic Complexity of Technological Change. Cheltenham: Edward Elgar.

Antonelli, C. 2013a. "Knowledge governance, pecuniary knowledge externalities and total factor productivity growth.” Economic Development Quarterly 27, 62-70.

Antonelli, C. 2013b. "Compulsory licensing: The foundations of an institutional innovation." WIPO Journal 4, 157-174.

Arrow, K. J. 1962. "Economic welfare and the allocation of resources for invention," in: Nelson, R. R. (ed.), The rate and direction of inventive activity: Economic and social factors. Princeton: Princeton University Press for N.B.E.R., pp. 609-625.

Arrow, K. J. 1969. "Classificatory notes on the production and transmission of technical knowledge." American Economic Review 59, 29-35.

Biatour, B., and M. Dumont. 2011. The determinants of industry-level total factor productivity in Belgium. Federal Planning Bureau Working Paper, 7-11.

Cameron, G., J. Proudman, and S. Redding. 2005. "Technological convergence, R\&D, trade and productivity growth.” European Economic Review 49, 775-807.

Cohen, W. M., and D. A. Levinthal. 1990. "Absorptive capacity: A new perspective on learning and innovation.” Administrative Science Quarterly 35, 128-152.

Crépon, B., E. Duguet, and J. Mairesse. 1998. "Research and development, innovation and productivity: An econometric analysis at the firm level." Economics of Innovation and New Technology 7, 115-158.

David, P. A. 1993. Knowledge property and the system dynamics of technological change. Proceedings of the World Bank Annual Conference on Development Economics, The World Bank, Washington.

Gehringer, A. 2011. "Pecuniary knowledge externalities and innovation: intersectoral linkages and their effects beyond technological spillovers." Economics of Innovation and New Technology 20, 495-515.

Gehringer, A. 2013. "Financial liberalization, growth, productivity and capital accumulation: The case of European integration." International Review of Economics \& Finance 25, 291-309.

Gehringer, A., I. Martínez-Zarzoso, and F. Nowak-Lehmann. 2014. TFP drivers in the European Union. University of Göttingencege-Diseussion paper, 189. 


\section{STRATEGIC ALLIANCES}

Griliches, Z. 1979. "Issues in assessing the contribution of research and development to productivity growth." Bell Journal of Economics 10, 92-116.

Griliches, Z. 1992. "The search for R\&D spillovers." Scandinavian Journal of Economics 94, $29-47$.

Grossman, G., and E. Helpman. 1991. Innovation and Growth in the Global Economy. Cambridge, MA and London, UK: MIT Press.

Krugman, P. (1994). "Complex landscapes in economic geography." American Economic Review 84, 412-417.

Krugman, P. (1995). Development Geography and Economic Theory. Cambridge, MA: MIT Press.

Lane, D. 2009. Complexity Perspectives in Innovation and Social Change, Vol. 7. Berlin: Springer.

Link, A., and D. Siegel. 2007. Innovation, Entrepreneurship, and Technological Change. Oxford: Oxford University Press.

Lucas, R. E. 1998. “On the mechanisms of economic development.” Journal of Monetary Economics 22, 3-42.

Lucas, R. E. 2008. "Ideas and growth.” Economica 76, 1-19.

Nelson, R. R. 1959. "The simple economics of basic scientific research.” Journal of Political Economy 67, 297-306.

Nelson, R. R. 1982. "The role of knowledge in R\&D efficiency." Quarterly Journal of Economics 97, 453-470.

Page, S. (2011). Diversity and Complexity. Princeton (Primers in Complex Systems): Princeton University Press.

Rivera-Batiz, L. A., and P. M. Romer. 1991. "Economic integration and economic growth." Quarterly Journal of Economics 106, 531-556.

Romer, P. M. 1990. "Endogenous technological change.” Journal of Political Economy 98, 71-102.

Saviotti, P. P. 2007. "On the dynamics of generation and utilisation of knowledge: The local character of knowledge." Structural Change and Economic Dynamics 18, 387-408.

Saviotti, P. P., and A. Pyka. 2008. "Micro and macro dynamics: Industry life cycles intersectoral coordination and aggregate growth." Journal of Evolutionary 18, 167-182.

Schumpeter J. A. 1942. Capitalism, Socialism and Democracy, New York: Harper and Brothers.

Schumpeter, J. A. 1947. "The creative response in economic history." Journal of Economic History 7, 149-159

Scitovsky, T. 1954. "Two concepts of external economies." Journal of Political Economy 62, 143-151.

Stock, J. H., and M. Yog. 2005. "Testing for weak instruments in linear IV regression.” In: Andrews, D. W. K., and J. H. Stock, (eds), Identification and Inference for Econometric Models: Essays in Honor of Thomas Rothenberg. Cambridge: Cambridge University Press, pp. 80-108.

Weitzman, M. L. 1996. "Hybridizing growth theory." American Economic Review 86, 207-212.

Weitzman, M. L. 1998. "Recombinant growth.” Quarterly Journal of Economics 113, 331-360.

\section{Appendix A}

Table A.1 Correlation matrix between the excluded instruments and the dependent variable.

\begin{tabular}{lcclll}
\hline & $\Delta T F P$ & $S T O C K$ & $C K$ & $C K_{t-1}$ & $C K_{t-2}$ \\
\hline$\Delta T F P$ & 1 & & & & \\
STOCK & -0.011 & 1 & & & \\
$C K$ & -0.193 & -0.304 & 1 & 1 & \\
$C K_{t-2}$ & -0.190 & -0.304 & 0.980 & 0.051 & 1 \\
$C K_{t-2}$ & 0.083 & -0.069 & 0.052 & \\
\hline
\end{tabular}

\section{Appendix B}

The calculation of the stock of patents is based on the perpetual inventory method, analogously linke in the case of calculation of the stock of tangible capital (see, for instance, Gehringer 2013). Accordingly, the stock of patents in each year $t$ in country $i$ is given by

$$
\text { STOCK }_{i t}=(1-\delta) S T O C K_{i t-1}+F_{L O W}
$$




\section{STRATEGIC ALLIANCES}

where $F L O W_{i t}$ measures the current flow of patents and $\delta$ is a depreciation rate assumed constant and equal to 0.06 . Moreover, the initial level of the patent stock, $S T O C K_{i 0}$, is computed as

$$
\operatorname{STOCK}_{i 0}=F L O W_{i 0} / g+\delta
$$

where $g$ is a geometric average of the growth rate of investment over the whole period for which data on each year patent applications are available. This period ranges for the majority of countries in our sample between 1963 and 2011, with the exception of Australia (1995-2011), Belgium (1965-2011), Canada (1960-2011), Korea (1960-2011), Netherlands (1960-2011) and Spain (1965-2011).

\section{Taylor \& Francis Not for distribution}

